\title{
Capturing schizophrenia-like prodromal symptoms in a spinocerebellar ataxia-17 transgenic rat
}

\author{
Davide Amato ${ }^{1}$, Fabio Canneva ${ }^{2}$, Huu Phuc Nguyen ${ }^{3}$, Peter Bauer ${ }^{3}$, \\ Olaf Riess $^{3}$, Stephan von Hörsten ${ }^{2}$ and Christian P Müller ${ }^{1}$
}

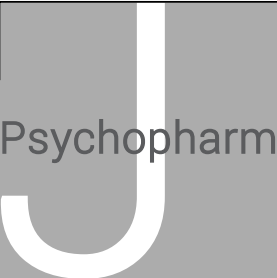

Journal of Psychopharmacology 2017, Vol. 31(4) 461-473 (c) The Author(s) 2016 Reprints and permissions: sagepub.co.uk/journalsPermissions.nav DOI: $10.1177 / 0269881116675510$ journals.sagepub.com/home/jop

@SAGE

\begin{abstract}
Rationale: The polyglutamine disease spinocerebellar ataxia type 17 (SCA17) is a neurodegenerative disease leading to severe neurological symptoms during development. Additionally, patients affected by SCA17 display psychosis earlier than their motor disorders.

Objective: Here the putative psychotic phenotype and endophenotype of transgenic SCA17 rats was examined.

Methods: The expression of schizophrenia-like symptoms was evaluated over a longitudinal period before and after the onset of neurological symptoms in SCA17. To this end, transgenic SCA17 rats' monoamine neurotransmission was investigated along with their locomotion at baseline and in response to amphetamine using in-vivo microdialysis in free moving conditions, their sensorimotor gating using pre-pulse inhibition of startle reaction, and their object memory using the novel object recognition test as an index of cognitive impairments.

Results: Presymptomatic SCA17 rats displayed dysregulated monoamine levels at baseline and in response to amphetamine compared with control wild-type (wt) rats. At that stage, neither amphetamine-induced hyperlocomotion nor sensorimotor gating differed from that in wt rats. Symptomatic SCA17 rats developed sensorimotor gating deficits and also showed an impaired object memory, while their monoaminergic responses remained supersensitive to amphetamine.

Conclusions: The data of the present study demonstrate a neurochemical endophenotype in SCA17 rats resembling that of prodromal schizophrenia. These findings suggest that a sensitization of the monoamine systems arises early in adulthood in SCA17 rats and may predispose them to express schizophrenia-like symptoms later in life.
\end{abstract}

Keywords

Spinocerebellar ataxia 17, schizophrenia, pre-pulse inhibition, dopamine, serotonin, in-vivo microdialysis

\section{Introduction}

Spinocerebellar ataxia type 17 (SCA17) is a rare autosomaldominant neurodegenerative disorder within the group of polyglutamine (polyQ) diseases caused by an expanded polyQ repeat in different proteins (Bauer and Nukina, 2009). While in other polyQ disorders a "gain of function" in mutant proteins may indirectly cause downstream transcriptional dysregulation (Bauer and Nukina, 2009), SCA17 is caused by an expansion of CAG repeats within the TATA box binding protein (TBP) coding gene (Koide et al., 1999), which is a ubiquitous transcription initiation factor. As a component of the transcriptional complex, TBP is the DNA-binding subunit of RNA polymerase II transcription factor D (TFIID), which activates the expression of most genes (van Roon-Mom et al., 2005). CAG repeats expansion mutation has been described in several neurodegenerative diseases, and was first described in Huntington's disease (HD) (Riley and Orr, 2006; Zoghbi and Orr, 2000).

Interestingly, patients affected by SCA17 or by other polyQrelated disorders display psychosis, often before developing full neurological symptoms (Rolfs et al., 2003; Tsuang et al., 1998, 2000). This clinical evidence would suggest the hypothesis of an involvement of polyQ expansions in the pathogenesis of schizophrenia. Accordingly, large polyQ regions are more common in schizophrenia and bipolar disorder than in healthy individuals
(Morris et al., 1995; O’Donovan et al., 1996; Ohi et al., 2009). In schizophrenia, a polyQ expansion was linked to chromosome 6q27 (Chen et al., 2005; Ohi et al., 2009), which was confirmed by a genome-wide linkage study (Hong et al., 2009).

The mechanism of action of polyQ expansion in promoting susceptibility to schizophrenia is unknown. It has been suggested that a toxic gain of function proportional to the size of the polyQ expansion may determine the severity and the age at onset of the disease (Jones et al., 1997; Morris et al., 1995; Rubinsztein et al., 1996). However, this association has proven to be equivocal

\footnotetext{
${ }^{1}$ Department of Psychiatry and Psychotherapy, Friedrich-AlexanderUniversity Erlangen-Nürnberg, Germany

2Department of Experimental Therapy, Preclinical Experimental Center, Friedrich-Alexander-University Erlangen-Nürnberg, Germany ${ }^{3}$ Institute of Medical Genetics and Applied Genomics, Rare Disease Center Tübingen, University of Tübingen, Germany
}

\section{Corresponding author:}

Davide Amato, Section of Addiction Medicine, Department of Psychiatry and Psychotherapy, Friedrich-Alexander-University ErlangenNürnberg, Ulmenweg 19, Erlangen 91054, Germany. Email: amatodavide@gmail.com, Davide.Amato@uk-erlangen.de 


\section{Experimental flow chart}

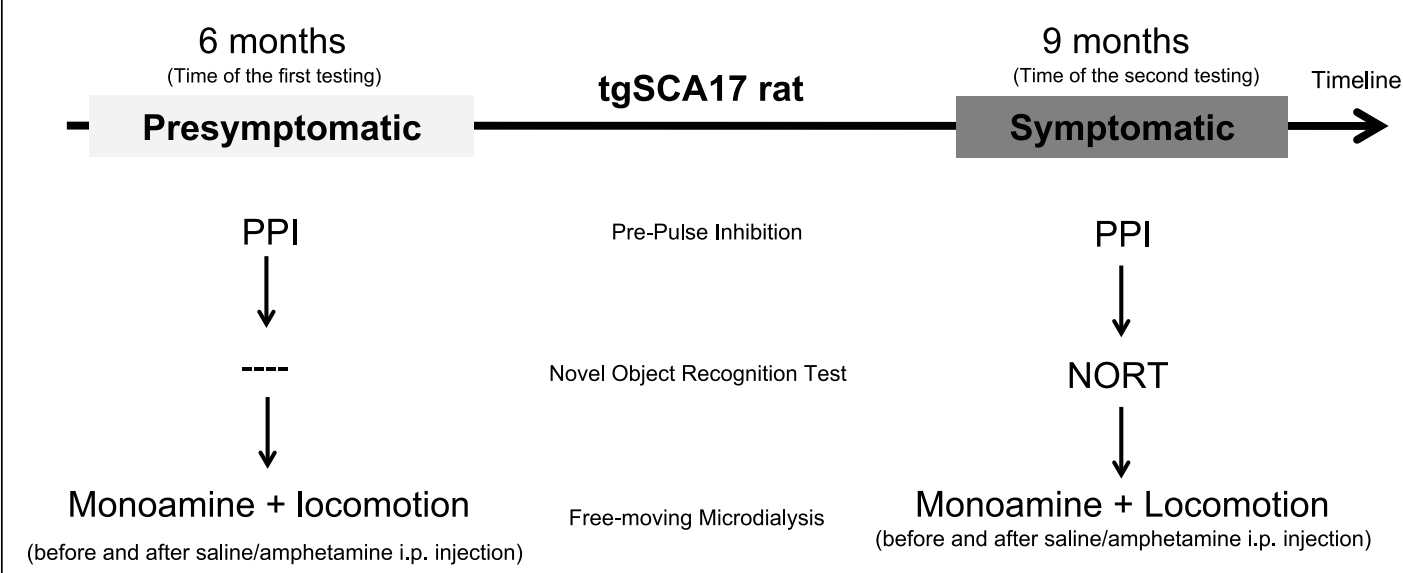

Figure 1. Experimental flow chart with the time-course of behavioural and neurochemistry studies. A total of 22 wt and 31 tgSCA17 rats were used at the beginning of the study. The exact number of animals used in each test is reported in Tables 1-3. Those animals tested as symptomatic for PPI of startle reflex were previously exposed to PPI at presymptomatic age. A selection of rats that participated in the PPI testing were also used for the microdialysis study. The time interval between PPI and microdialysis was 8-10 days, and between PPI and NORT it was 4-6 days. tg: transgenic.

(Claes et al., 1995; Gaitonde et al., 1997; Tsuang et al., 1998, 2000; Zappacosta et al., 1996), as polyQ expansion baseline can differ among ethnic groups (Sirugo et al., 1997).

In the present work, we describe the age-related expression of schizophrenia-like symptoms in SCA17-transgenic rats. SCA17 rats used in this study carry a human full-length DNA construct with $64 C A G$ repeats under the control of the endogenous rat huntingtin $(\mathrm{Htt})$ promoter. Previous characterizations have shown SCA17 transgenic rat to mirror crucial neurological symptoms (Urbach et al., 2009). Yet, putative schizophrenia-like symptoms in SCA17 rats have not been described. Here we focus on characterizing the monoaminergic and behavioural responses to amphetamine (d-amphetamine hemisulfate salt (AMPH)) at presymptomatic and symptomatic ages of transgenic SCA17 rats, referring to a previous longitudinal categorization of the model (Urbach et al., 2009). Dysregulation of monoaminergic neurotransmitter systems is a consolidate biomarker for the neurobiology of psychosis in humans (Howes et al., 2012), and its relationship with locomotion is a widely used animal model of psychosis (Robinson and Becker, 1986). In addition, we have characterized SCA17's putative sensorimotor gating changes over the longitudinal study as a marker of psychotic symptom progression in the animal model.

At a symptomatic age, after detecting PPI deficits, we have also assessed rats' object recognition memory as an index of their cognitive performance. We hypothesized that SCA17 rats would exhibit a schizophrenia-like phenotype upon development of a supersensitive monoaminergic system.

\section{Methods and materials}

\section{Animals}

The SCA17 rats used in this study were homozygous male transgenic Sprague-Dawley rats expressing a full-length human TBP construct containing $64 C A G$ repeats under the control of the rat Htt promoter (Holzmann et al., 1998; Urbach et al., 2009; von Horsten et al., 2003). The inbred colony was maintained through het:het mating and regularly genotyped by quantitative polymerase chain reaction (qPCR). Thus, control wild-type (wt) animals were littermates of SCA17 rats. Rats were housed in groups of four per cage with a temperature of $22 \pm 2^{\circ} \mathrm{C}$ (relative humidity $55 \pm 10 \%$ ), a 12:12 light:dark cycle (light on at 7:00 h, light off at 19:00 h), and food and water provided ad libitum. All procedures used followed the guidelines of international standards for the care and use of laboratory animals and were approved by the local Animal Welfare and Ethics committee of the Bavarian state, Germany (protocol Az. 54-2532.1-20/10).

\section{Study design}

A total of 31 SCA17 and $22 \mathrm{wt}$ male rats participated in the longitudinal study, in which we measured acoustic sensorimotor gating response using pre-pulse inhibition (PPI) and the dopamine and locomotion responses to d-amphetamine hemisulfate salt (AMPH; Sigma-Aldrich, Germany) at either presymptomatic (6 months old; body weight mean, wt: $456 \pm 36$ g, SCA17: $453 \pm 71$ g) or symptomatic age ( 9 months old; body weight mean, wt: 570 $\pm 60 \mathrm{~g}$, SCA17: $553 \pm 73 \mathrm{~g}$ ), as defined in a previous characterization (Urbach et al., 2009). Novel object recognition memory was assessed at symptomatic age only. The sequence of the experiments carried out in the present study is illustrated in the flow chart (Figure 1). Rats that participated in the microdialysis study were no longer used for other tests to prevent any putative alteration of normal behaviour due to the brain microdialysis cannula implants. Thus, only the remaining former presymptomatic animals were then used for the tests at symptomatic age. In this study we focused on male rats only because of their behavioural consistency compared with female rats, which are influenced by complex hormonal fluctuations. 


\section{PPI of the acoustic startle response (ASR)}

ASR was measured in a standard Startle Response System (TSE Systems, Bad Homburg, Germany), as previously described (Urbach et al., 2014). Four animals were tested in parallel in individual soundproof boxes after being placed into a restraining metal cage $(27 \times 9 \times 10 \mathrm{H} \mathrm{cm})$ that was tightly anchored to a piezoaccelerometer, allowing the accurate recording of bodyweight changes, and therefore movements, of the animal inside the cage. Two loudspeakers positioned at the right and left of the restraining unit delivered the test noises according to protocols that were designed and controlled by a computer. White noise was used throughout the testing procedure, and an intensity of $68 \mathrm{~dB}$ provided the constant background.

Each protocol consisted of 10 initial repetitions of a startling stimulus $(120 \mathrm{~dB}, 20 \mathrm{~ms})$ followed by a randomly distributed combination of: (a) 40 inhibitory trials composed of a pre-pulse stimulus $(72,76,80$ or $84 \mathrm{~dB}, 20 \mathrm{~ms})$ followed, after $100 \mathrm{~ms}$, by a startling stimulus; (b) 15 repetitions of a startling stimulus (in order to control for time-dependent habituation/decrease of the startle response); (c) 12 repetitions of the pre-pulse stimulus alone (3 repetitions for each pre-pulse intensity), in order to experimentally prove no startle reaction to those noises.

We used four pre-pulse intensities as they are typically applied to validate the intensity-specific effect of the pre-pulse in determining PPI (the higher the pre-pulse, the bigger the PPI). Such a result is very important in determining whether PPI deficits relate to the amplitude of the response or more generally to lack of response to the manipulation. Throughout the test, a pseudo-random inter-trial interval (ITI) of 6-12 s was defined. The ITI interval, as well as randomization of the trials' presentation, ensures that no cognitive (predictive) adaptation to the protocol can interfere with the response of the animals to the test.

The whole experiment consisted of 77 trials and lasted about $14 \mathrm{~min}$. The ASR response amplitude was averaged across trials for each noise intensity, tested and expressed as arbitrary units (g). PPI was then calculated as the percentage inhibition obtained for each pre-pulse intensity as compared with the startle elicited by the 10 initial trials, according to the following formula: $100-\left[\left(\text { ASR }^{\text {(PPI trials) }} / \mathrm{ASR}^{\text {(startling trials) }}\right)^{*} 100\right]$.

For each age point tested, average PPIs measured at different pre-pulse intensities were calculated, and a three-way analysis of variance (ANOVA) for repeated measures was used to analyse the effect of the factors age, genotype and pre-pulse intensity.

\section{Novel object recognition}

The novel object recognition test (NORT) was performed as described previously (Bevins and Besheer, 2006). Animals' movements were monitored throughout all phases of testing using video tracking software (Viewer, NewBehavior, Germany), which allowed the automated detection of distance walked as well as number of interactions and time spent exploring each of the objects available to the animals. The experiment was performed on two consecutive days. On the first day, the rats were habituated to the testing arena and allowed to explore the new environment for $15 \mathrm{~min}$. On the following day, rats were returned to the same arena, and exploratory behaviour was assessed during two consecutive sessions ( $\mathrm{S} 1$ and S2), interspaced by 2 hours. During S1, animals were allowed to explore two identical objects (plastic ducks) for $10 \mathrm{~min}$, while during S2, one of the two objects was replaced with an unfamiliar one (a Lego tower), and exploratory activity was measured for $5 \mathrm{~min}$. Animals were exposed to the same object combination. For each experimental session, the time spent by the animal exploring the unfamiliar object, or the object previously located in the same position, was calculated as a percentage of the total time spent exploring both objects. Animals that failed to explore each of the two identical objects for at least $5 \mathrm{~s}$ during S1 were excluded from the study. Object exploration was defined as any approach of the animals to the object with their head (e.g. licking, sniffing). Also, the exploratory activity of SCA17 and wt rats was monitored during the 15 min of habituation to the testing arenas on day 1. Additionally, the time spent in the arena centre, as a measure of anxiety, was recorded.

\section{In-vivo microdialysis and locomotion}

Dopamine (DA) and serotonin (5-HT) are believed to be crucial mediators for schizophrenia-like symptoms and their treatment (Howes and Kapur, 2014; Quednow et al., 2010). Therefore, we measured DA and 5-HT basal and induced extracellular activity in SCA17 rats. Animals were anaesthetized with a mixture of Ketamine $(0.9 \mathrm{mg} / \mathrm{kg})$, Medetomidine $(0.4 \mathrm{mg} / \mathrm{kg})$ and sterile water. They also received $0.1 \mathrm{mg}$ Novalminsulfate s.c. for analgesia. After identification of bregma (Paxinos and Watson, 1986), two guide cannulae (MAB 6.14.IC, Microbiotech, Stockholm, Sweden) were implanted on each animal, targeting the caudate putamen $(\mathrm{CPu}$; anterior/posterior $(\mathrm{A} / \mathrm{P})$ : \pm 0.0 ; medial/lateral $(\mathrm{M} / \mathrm{L}): \pm 3.5 ;$ dorsal $/$ ventral $(\mathrm{D} / \mathrm{V}):-4.0 ; 10^{\circ}$ to the midline $)$ and nucleus accumbens (NAcc; A/P: $+1.6 ; \mathrm{M} / \mathrm{L}: \pm 2.6 ; \mathrm{D} / \mathrm{V}:-5.8 ; 10^{\circ}$ to the midline), respectively (Amato et al., 2011a, 2011b). Animals were allowed 4-5 days' recovery before being tested. A proportion of the animals that participated in the PPI testing were used for the microdialysis study. The time interval between PPI and microdialysis was 8-10 days.

Fourteen hours before the beginning of the experiments, rats were anaesthetized using isoflurane, and microdialysis probes (Microbiotech, Stockholm, Sweden) with a membrane length of $2 \mathrm{~mm}$ (MAB 6.14.2; NAcc) or $3 \mathrm{~mm}$ (MAB 6.14.3; $\mathrm{CPu}$ ) and a molecular 'cut off' of $15 \mathrm{kDa}$ were inserted into the guide cannulae. Rats were put into an open field $(40 \times 40 \times 39 \mathrm{~cm})$ of a TruScan system (Coulbourn Instruments, Allentown, USA) and the microdialysis probes were perfused with artificial cerebrospinal fluid (aCSF) with a flow rate of $0.05 \mathrm{~mL} / \mathrm{min}$ overnight. On the next day, $3 \mathrm{~h}$ before the test, the flow rate was gradually increased to $1.5 \mathrm{~mL} / \mathrm{min}$. Then, samples were taken every 20 min. Three samples were collected before AMPH ( $1 \mathrm{mg} / \mathrm{kg}$, i.p.) or saline (SAL, $1 \mathrm{~mL} / \mathrm{kg}$, i.p.) injection as a baseline and six samples thereafter. Locomotion was automatically recorded during the experiment (Amato et al., 2015). At the end of the experiment, rats were anaesthetized deeply and decapitated. Only those rats with correctly targeted brain areas were considered for further data analysis.

Microdialysis samples were immediately analysed after collection using high-performance liquid chromatography with 


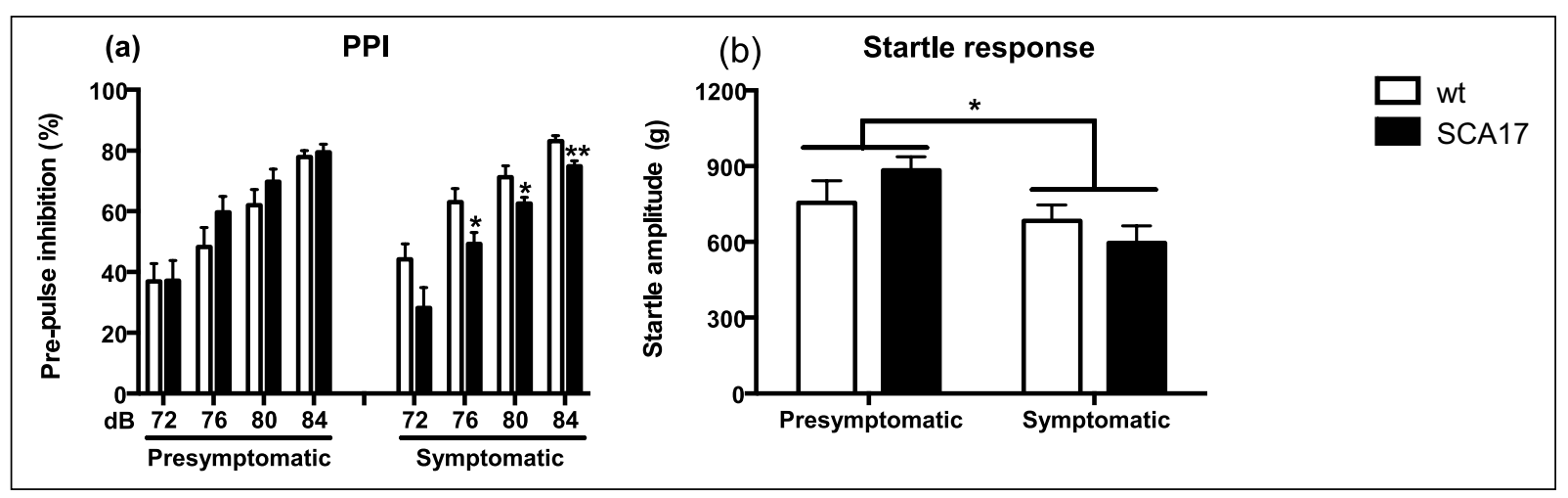

Figure 2. Pre-pulse inhibition (PPI) measured in presymptomatic and symptomatic SCA17 rats. (a) There was a significant effect of the genotype, and an interaction with the age of the animals at testing, exemplified by a reduced PPI in symptomatic SCA17 as compared with wt. (b) The overall startle response decreased with aging in all rats $\left({ }^{*} p<0.05,{ }^{* *} p<0.01\right.$ vs. wt).

electrochemical detection. The column was an ET 125/2, Nucleosil 120-5, C-18 reversed phase column (Macherey \& Nagel, Germany) perfused with a mobile phase composed of 75 $\mathrm{mM} \mathrm{NaH} \mathrm{PO}_{4}, 4 \mathrm{mM} \mathrm{KCl}, 20 \mathrm{mM}$ EDTA, $1.5 \mathrm{mM}$ SDS, 100 $\mathrm{mL} / \mathrm{L}$ diethylamine, $12 \%$ methanol and $12 \%$ acetonitrile, adjusted to $\mathrm{pH} 6.0$ using phosphoric acid. The electrochemical detector (Intro, The Netherlands) was set at $500 \mathrm{mV}$ vs. an ISAAC reference electrode (Antec, The Netherlands) at $30{ }^{\circ} \mathrm{C}$. This set-up allows the measurement of 5-HT and DA. The detection limit of the assay was $0.1 \mathrm{pg}$ for 5-HT and DA, with a signal-to-noise ratio of 2:1. Neurochemical data were not corrected for recovery (Amato et al., 2011a, 2011b).

\section{Statistics}

Behavioural results were analysed using ANOVA tests for repeated measures. Fisher's least significant difference (LSD) pre-planned tests were used to quantify statistically significant differences between experimental groups. A chi-square test was used as a post-hoc test to evaluate the inter-individual recognition index during NORT between genotypes.

DA and 5-HT levels at baseline were compared between genotypes as absolute values using the $t$-test analysis. Changes in DA and 5-HT extracellular levels in response to AMPH were calculated as baseline \% change and analysed compared with baseline and vehicle-treated groups (mean \pm standard error (SEM)). Neurochemical responses to AMPH in wt and SCA17 rats were analysed using twoway ANOVA and pre-planned comparisons with Fisher's LSD test. A $p$-value $<0.05$ was considered significant.

\section{Results}

\section{SCA17 deficits in pre-pulse inhibition at symptomatic, but not at presymptomatic, age}

Statistical differences between SCA17 and wt rats were found at the symptomatic, but not at the pre-symptomatic, age using prepulse intensities of 76, 80 and $84 \mathrm{~dB}$ (Figure 2(a) and Table 1). Data collected from animals tested at both presymptomatic and symptomatic ages were analysed using a three-way ANOVA for repeated measures. Besides the effect of the factor Pre-Pulse
Intensity $\left(F_{3,20}=69.805, p<.0001\right)$, a significant effect of the factor Genotype was revealed $\left(F_{1,22}=6.104, p<.05\right)$, along with a significant interaction with the age of the animals $\left(F_{2,21}=8.305\right.$, $p<.0005)$. In particular, pre-planned analysis revealed a significant difference between wt and SCA17 rats at symptomatic, but not presymptomatic, age at most pre-pulse intensities tested (76 $\mathrm{dB}: p<.05 ; 80 \mathrm{~dB}: p=0.05 ; 84 \mathrm{~dB}: p<.005)$. Of note, overall startle amplitude to the $120 \mathrm{~dB}$ noise trials was not different between genotypes (Figure 2(b)). However, it decreased in both groups during the symptomatic period $\left(F_{1,78}=6.036, p<.05\right)$.

\section{Novel object recognition is impaired in SCA17 rats at symptomatic age}

Overall, explorative drive and horizontal locomotion during the habituation phase of the test were similar in both genotypes tested $\left(F_{1,29}=0.4818, p=.5\right.$; Figure 3(a)). Also, the time spent in the centre of the arena was similar in both genotypes, thus indicating no obvious anxiety phenotype in SCA17 rats (two-tailed $t$-test, $p=.9$; Figure 3(b)). Time spent with the unfamiliar object during session 2 (S2) on the second day of testing was used as a measure of the recognition index in the task, and compared with the time spent exploring the old object in the same position on the previous session (Figure 4(a)). Both SCA17 and wt rats spent significantly more time with the new object $\left(F_{1,27}=16.62\right.$, $p<.001)$, although the preference was much higher in wt rats $(p<.001)$ than in SCA17 rats $(p<.05)$. The exploration of the new object during session S2 did not differ significantly between SCA17 and wt rats. However, a careful analysis of the distribution of individual performance around the median performance of each group revealed a significant difference between genotypes (chi-square test, $p<.05$; Figure $4(\mathrm{~b})$ ). These findings suggest the occurrence of a modest, but significant, cognitive deficit in SCA17 rats at symptomatic age.

\section{Altered basal monoamine levels in SCA17 rats at presymptomatic and symptomatic ages}

Extracellular DA levels at baseline were significantly reduced in SCA17 animals in the NAcc, but not in the $\mathrm{CPu}$, already at a presymptomatic age (Table 2). In addition, basal 5-HT levels 
Table 1. Pre-pulse inhibition of the acoustic startle response in wt and SCA17 (presymptomatic/symptomatic) rats.

\begin{tabular}{|c|c|c|c|c|c|c|}
\hline Age & Test & Genotype & $n$ & mean $\pm S D$ & $F(D F n, D f d)$ & $p$ \\
\hline \multirow[t]{2}{*}{ Presymptomatic } & Acoustic startle $120 \mathrm{~dB}$ & SCA17 & 31 & $883.4 \pm 299.1$ & $F(21,30)=2.220$ & .436 \\
\hline & & wt & 22 & $797.4 \pm 445.7$ & & \\
\hline \multirow[t]{2}{*}{ Symptomatic } & Acoustic startle $120 \mathrm{~dB}$ & SCA17 & 15 & $595.2 \pm 264.4$ & $F(14,14)=1.203$ & .7341 \\
\hline & & wt & 15 & $683.9 \pm 241.1$ & & \\
\hline \multirow[t]{8}{*}{ Presymptomatic } & PPI $72 \mathrm{~dB}$ & SCA17 & 27 & $35.1 \pm 25.8$ & $F(1,40)=0.3477$ & .5587 \\
\hline & & wt & 15 & $42.5 \pm 20.1$ & & \\
\hline & PPI $76 \mathrm{~dB}$ & SCA17 & 27 & $53.1 \pm 19.5$ & & \\
\hline & & wt & 15 & $55.5 \pm 22.9$ & & \\
\hline & PPI $80 \mathrm{~dB}$ & SCA17 & 27 & $67.4 \pm 13.7$ & & \\
\hline & & wt & 15 & $66.4 \pm 16.5$ & & \\
\hline & PPI $84 \mathrm{~dB}$ & SCA17 & 27 & $78.2 \pm 9.6$ & & \\
\hline & & wt & 15 & $80.9 \pm 8.1$ & & \\
\hline \multirow[t]{8}{*}{ Symptomatic } & PPI $72 \mathrm{~dB}$ & SCA17 & 12 & $28.1 \pm 23.7$ & $F(1,21)=7.871$ & .0106 \\
\hline & & wt & 11 & $44.2 \pm 16.5$ & & \\
\hline & PPI $76 \mathrm{~dB}$ & SCA17 & 12 & $49.2 \pm 13.3$ & & \\
\hline & & wt & 11 & $62.9 \pm 15.1$ & & \\
\hline & PPI $80 \mathrm{~dB}$ & SCA17 & 12 & $62.5 \pm 7.2$ & & \\
\hline & & wt & 11 & $71.2 \pm 12.5$ & & \\
\hline & PPI $84 \mathrm{~dB}$ & SCA17 & 12 & $74.8 \pm 6.0$ & & \\
\hline & & wt & 11 & $83.2 \pm 5.8$ & & \\
\hline \multirow[t]{4}{*}{ Symptomatic } & NORT S1 & SCA17 & 14 & $46.2 \pm 13.3$ & $F(1,27)=1.736$ & .1987 \\
\hline & & wt & 15 & $47.7 \pm 17.7$ & & \\
\hline & NORT S2 & SCA17 & 14 & $58.4 \pm 18.0$ & & \\
\hline & & wt & 15 & $68.8 \pm 15.9$ & & \\
\hline
\end{tabular}

Note: Bold value refers to statistic significance.

$\mathrm{DFn}$ : degree of freedom numerator (k-1); DFd: degree of freedom denominator $(\mathrm{N}-\mathrm{k})$.

were significantly reduced in SCA17 rats in both the NAcc and the $\mathrm{CPu}$. At symptomatic age, $\mathrm{SC} 17$ rats showed significantly enhanced DA levels in the NAcc, but no change in the $\mathrm{CPu}$ (Table 2). Basal 5-HT levels were not significantly different in either brain region between the genotypes. These results suggest that monoaminergic systems are already changed in their basal activity at a time when neither neurological nor schizophrenialike behavioural symptoms manifest.

\section{Sensitized monoamine responses in SCA17 rats at presymptomatic age}

AMPH led to a significant increase in extracellular DA levels in the NAcc of wt rats (Figure 5(a) and Table 3). This effect was massively potentiated in SCA17 rats at presymptomatic age. No effect was observed after SAL injection in either genotype (treatment: $F_{1,203}=22.51, p<.0001$ ). Pre-planned comparisons revealed significant differences between SCA17 and wt rats in extracellular DA levels $20 \min (p<.01), 40 \min (p<.001), 60 \min (p<.001)$ and $80 \mathrm{~min}(p<.001)$ after injection. AMPH led to a significant increase in extracellular 5-HT levels in the NAcc of wt rats (Figure 5(b)). This effect was massively potentiated in SCA17 rats at presymptomatic age. No effect was observed after SAL injection in either genotype (treatment: $F_{1,203}=16.43, p<.0001$ ). Pre-planned comparisons revealed significant differences between SCA17 and wt rats in extracellular 5-HT levels $40 \mathrm{~min}(p<.001), 60 \mathrm{~min}$ $(p<.01)$ and $80 \mathrm{~min}(p<.05)$ after AMPH injection.
In the $\mathrm{CPu}, \mathrm{AMPH}$ increased extracellular DA levels in wt rats (Figure 5(c)). This effect was potentiated in SCA17 rats. No effect was observed after SAL injections in either genotype (treatment: $F_{1,194}=34.59, p<.0001$, Table 3). Pre-planned comparisons revealed significant differences between SCA17 and wt rats in extracellular DA levels $40 \mathrm{~min}(p<.01), 60 \mathrm{~min}(p<.01), 80$ $\min (p<.01)$ and $100 \mathrm{~min}(p<.05)$ after AMPH injection.

In the $\mathrm{CPu}, \mathrm{AMPH}$ induced a small increase in extracellular 5-HT levels in wt rats (Figure 5(d)). This effect was potentiated in SCA17 rats. No effect was observed after SAL injections in either genotype (treatment: $F_{1,230}=25.29, p<.0001$ ). Pre-planned comparisons revealed significant differences between SCA17 and wt rats in extracellular 5-HT levels $40 \mathrm{~min}(p<.001), 60 \mathrm{~min}(p<.001)$, $80 \mathrm{~min}(p<.001)$ and $100 \mathrm{~min}(p<.01)$ after AMPH injection.

\section{Sensitized monoamine responses in SCA17 rats at symptomatic age}

AMPH led to a significant increase in extracellular DA levels in the NAcc of wt rats (Figure 6(a)). This effect was potentiated in SCA17 rats at symptomatic age. No effect was observed after SAL injections in either genotype (treatment: $F_{1,185}=17.31$, $p<.0001$, Table 3 ). Pre-planned comparisons revealed significant differences between SCA17 and wt rats in extracellular DA levels 40 min after AMPH injection $(p<.05)$. AMPH led to a significant increase in extracellular 5-HT levels in the NAcc of wt rats (Figure 6(b)). This effect was potentiated in SCA17 rats at 


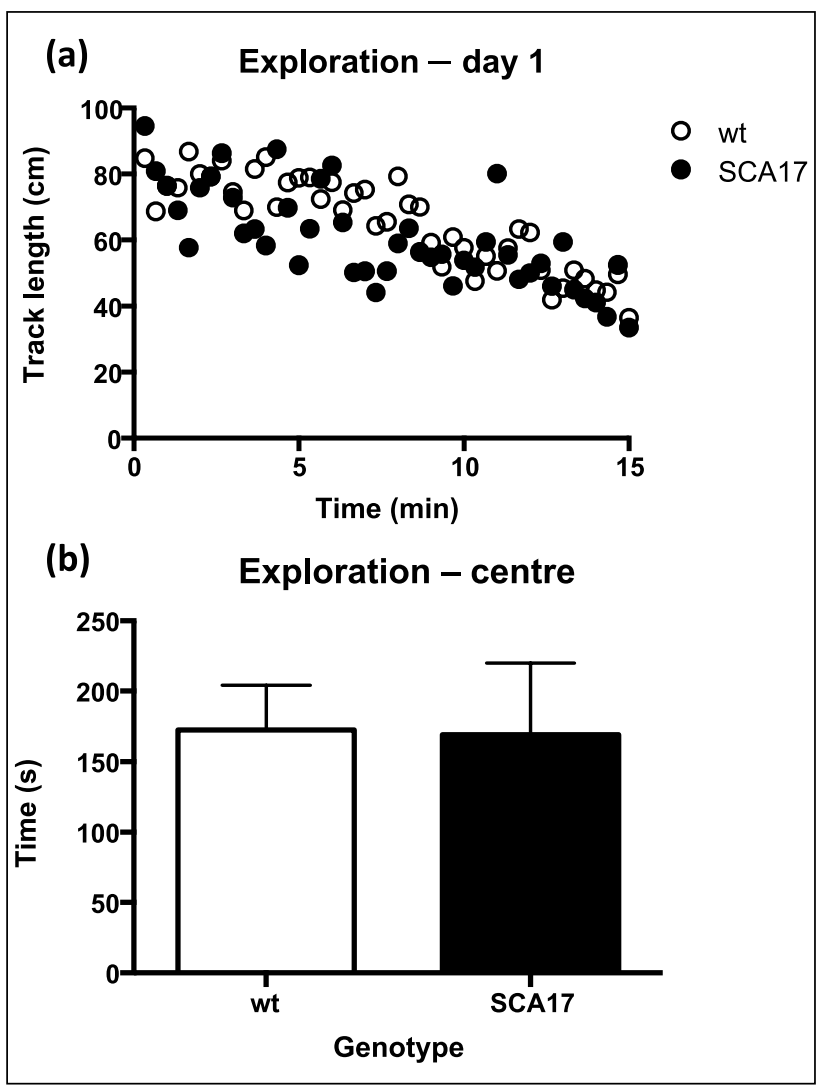

Figure 3. Object memory in symptomatic SCA17 rats. (a) Average horizontal exploration (track-length) of the novel object recognition test in wt and SCA17 rats. (b) Total time spent in the centre of the arena. Overall, the data indicate similar locomotor and emotional response in wt and SCA17s rats to the test conditions.

symptomatic age. No effect was observed after SAL injections in either genotype (treatment: $F_{1,203}=11.73, p<.0008$ ). Pre-planned comparisons revealed significant differences between SCA17 and wt rats in extracellular 5-HT levels 40 min after AMPH injection $(p<.05)$.

In the $\mathrm{CPu}, \mathrm{AMPH}$ increased extracellular DA levels in wt rats (Figure 6(c)). This effect was potentiated in SCA17 rats at symptomatic age. No effect was observed after SAL injections in either genotype (treatment: $F_{1,185}=22.81, p<.0001$, Table 3). Preplanned comparisons revealed significant differences between SCA17 and wt rats in extracellular DA levels 60 min after AMPH injection $(p<.05)$. In the $\mathrm{CPu}, \mathrm{AMPH}$ increased extracellular 5-HT levels in wt rats (Figure 6(d)). Visual inspection of the data suggests that this effect was marginally enhanced in SCA17 rats at symptomatic age (treatment: $F_{1,185}=18.83, p<.0001$ ). No effect was observed after SAL injections in either genotype. Preplanned comparisons did not show significant differences between SCA17 and wt rats at single time points $(p>0.05)$.

\section{Induced locomotion is impaired in}

SCA17 rats at symptomatic, but not at presymptomatic, age

Basal locomotor activity was analysed in all experimental groups before injections using a three-way ANOVA for repeated

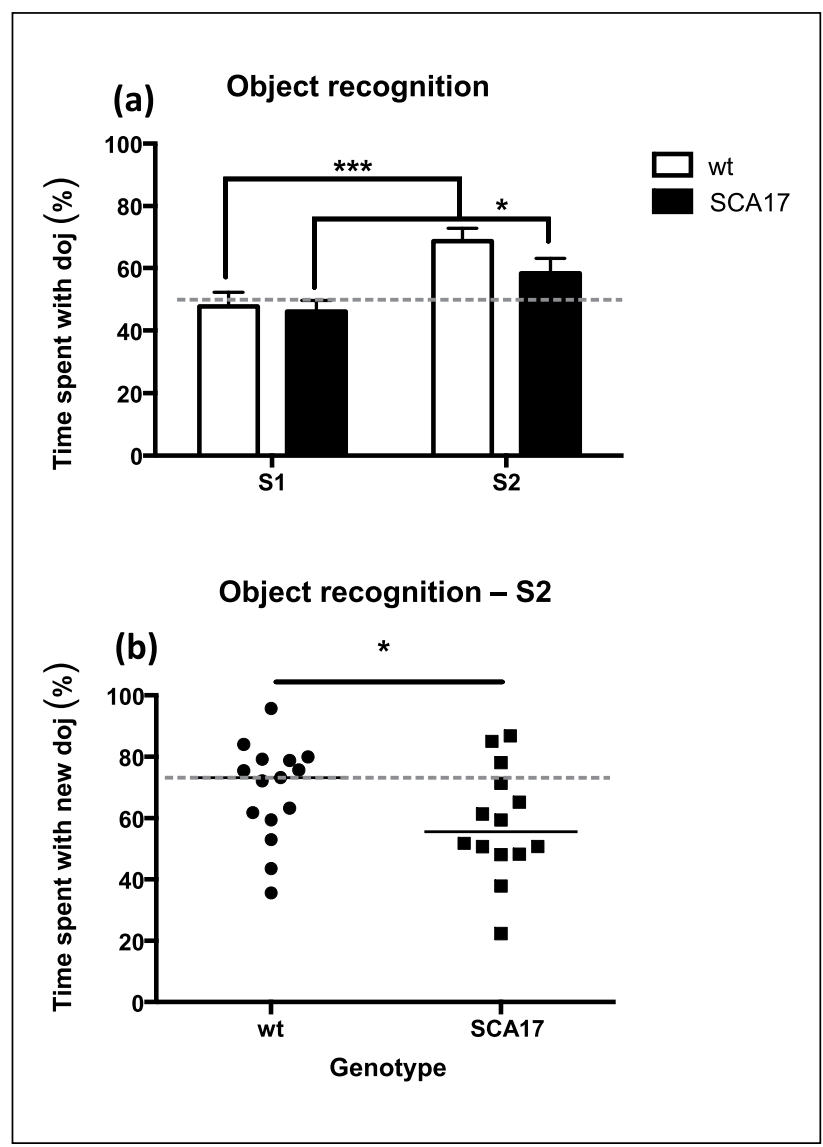

Figure 4. (a) Percentage of time spent by SCA17 and wt rats in exploring the new object during session 2 (S2) compared with exploration of the object placed in the same position during the previous session 1 (S1). (b) Median distribution of SCA17 rats during the new object recognition in $\mathrm{S} 2\left({ }^{*} p<.05,{ }^{* *} p<.001 \mathrm{vs} \mathrm{wt}\right)$.

measures, with the factors Genotype, Age and Treatment. At baseline, no significant differences were revealed between genotypes and treatments ( $p>.05$; Figure 7(a) to (b)). Although older animals at symptomatic age displayed significantly reduced locomotion $\left(F_{1,48}=4.947, p=.0316\right)$, there was no difference between genotypes $(p>.05)$.

The injection of AMPH induced a significant increase in locomotion in both wt and SCA17 rats as compared with SAL-treated animals at a presymptomatic age (Figure 7(a)). In particular, we found a significant treatment $\left(F_{3,207}=31.42, p<.0001\right)$ and time effect $\left(F_{8,207}=3.626, p=.0006\right)$ and a significant interaction $\left(F_{24,207}=1.592, p=.045\right)$. Statistical analysis indicated enhanced locomotion in the SCA17 rats compared with wt rats 20 and 40 min after AMPH injection $(p<.05)$. However, this may not indicate enhanced behavioural sensitivity. It is, rather, due to a baseline shift in the SCA17-AMPH group that was not observed in the SCA17-SAL group.

AMPH also led to a significant increased locomotion in wt and symptomatic SCA17 rats (Figure $7(\mathrm{~b})$ ). Particularly, we found a significant treatment $\left(F_{3,180}=34.76, p<.0001\right)$ and time effect $\left(F_{8,180}=16.94, p<.0001\right)$ and a significant interaction $\left(F_{24,180}=2.534, p=.0003\right)$. The AMPH-induced hyperlocomotion was attenuated in the SCA17 rats 20 min after injection $(p=.0095)$ at symptomatic age. These data suggest that there were no gross 
Table 2. Extracellular dopamine (DA) and serotonin (5-HT) basal levels in wt and SCA17 (presymptomatic/symptomatic) rats measured by in-vivo microdialysis in freely moving conditions.

\begin{tabular}{|c|c|c|c|c|c|c|}
\hline Age & Brain region & Genotype & $\begin{array}{l}\mathrm{DA} \text { in } \mathrm{pg} / 30 \mu \mathrm{L} \\
\left(\text { mean }_{ \pm} \mathrm{SD}\right)\end{array}$ & $p$ & $\begin{array}{l}5-\mathrm{HT} \text { in } \mathrm{pg} / 30 \mu \mathrm{L} \\
(\text { mean } \pm \mathrm{SD})\end{array}$ & $p$ \\
\hline \multirow[t]{4}{*}{ Presymptomatic } & NAcc & SCA17 & $1.742 \pm 1.443$ & $<.028$ & $3.025 \pm 2.835$ & $<.002$ \\
\hline & & wt & $4.282 \pm 4.1$ & & $12.77 \pm 9.96$ & \\
\hline & $\mathrm{CPu}$ & SCA17 & $3.913 \pm 2.277$ & $>.05$ & $4.987 \pm 7.423$ & $<.028$ \\
\hline & & wt & $6.173 \pm 5.347$ & & $11.86 \pm 10.03$ & \\
\hline \multirow[t]{4}{*}{ Symptomatic } & NAcc & SCA17 & $4.936 \pm 5.413$ & $<.036$ & $5.164 \pm 7.376$ & $>.05$ \\
\hline & & wt & $1.762 \pm 2.519$ & & $2.923 \pm 5.268$ & \\
\hline & $\mathrm{CPu}$ & SCA17 & $3.955 \pm 4.063$ & $>.05$ & $5.918 \pm 8.371$ & $>.05$ \\
\hline & & wt & $3.633 \pm 8.166$ & & $4.225 \pm 6.576$ & \\
\hline
\end{tabular}

Note: Bold value refers to statistic significance.

\section{Presymptomatic}

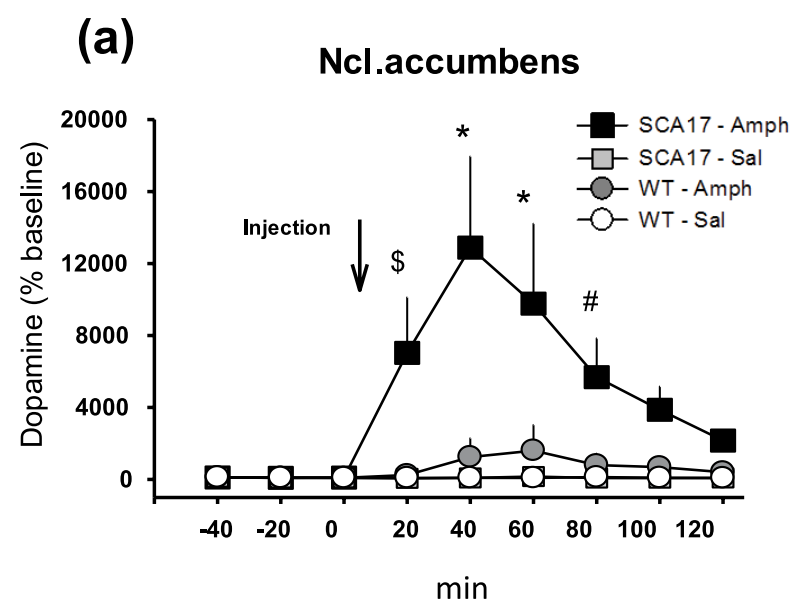

(c)

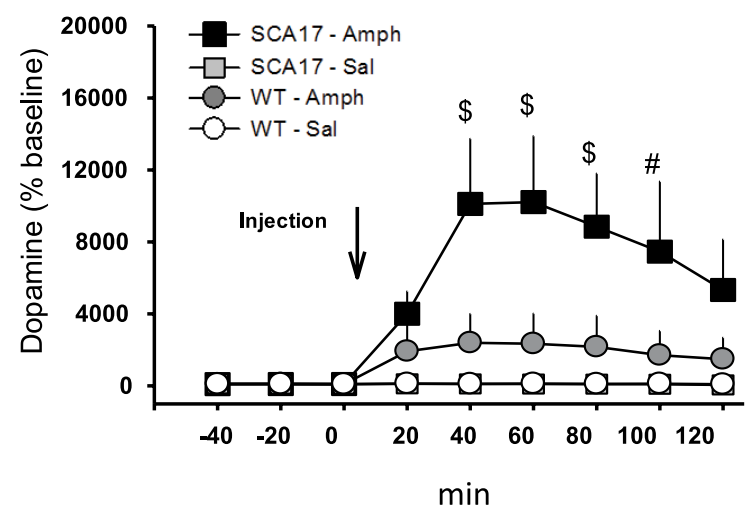

(b)

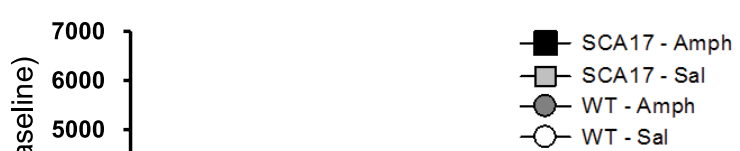

- - WT - Sal

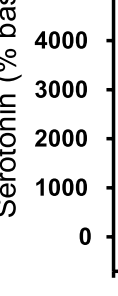

(d)

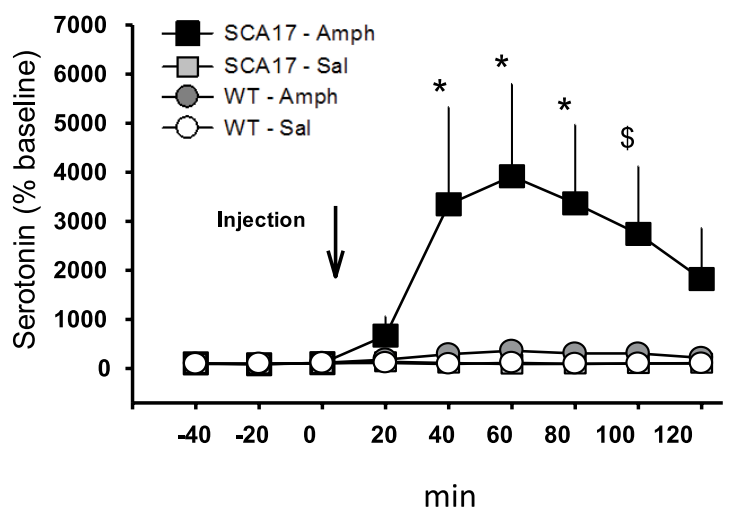

Figure 5. Amphetamine (AMPH; $1 \mathrm{mg} / \mathrm{kg}$, i.p.) or saline (Sal) effects on extracellular dopamine and serotonin levels in presymptomatic SCA17 and wt rats measured by in-vivo microdialysis in freely moving animals. (a) Nucleus accumbens - dopamine. (b) Nucleus accumbens - serotonin. (c) Caudate putamen - dopamine. (d) Caudate putamen - serotonin $\left({ }^{*} p<.05,{ }^{* *} p<.01,{ }^{* * *} p<.001 \mathrm{vs} \mathrm{wt}\right)$. 
Table 3. Dopamine and serotonin responses (\% change) to amphetamine ( $1 \mathrm{mg} / \mathrm{kg}$, i.p.) or saline in wt and SCA17 (presymptomatic/symptomatic) rats measured by in-vivo microdialysis in freely moving conditions.

\begin{tabular}{|c|c|c|c|c|c|c|}
\hline Age & Brain region & & & $F$ & $\mathrm{dfs}$ & $p$ \\
\hline \multirow{12}{*}{$\begin{array}{l}\text { Presymptomatic } \\
\text { (SCA17: } n=6 / \text { group, } \\
\text { wt: } n=5-6 / \text { group) }\end{array}$} & \multirow[t]{6}{*}{ NAcc } & \multirow[t]{3}{*}{ DA } & Genotype & 14.55 & 1,203 & $<.0002$ \\
\hline & & & Treatment & 22.51 & 1,203 & $<.0001$ \\
\hline & & & Genotype $\times$ treatment & 14.57 & 1,203 & .0002 \\
\hline & & \multirow[t]{3}{*}{$5-\mathrm{HT}$} & Genotype & 11.19 & 1,203 & $<.001$ \\
\hline & & & Treatment & 16.43 & 1,203 & $<.0001$ \\
\hline & & & Genotype $\times$ treatment & 10.75 & 1,203 & .0012 \\
\hline & \multirow[t]{6}{*}{$\mathrm{CPu}$} & \multirow[t]{3}{*}{ DA } & Genotype & 12.4 & 1,194 & $<.0001$ \\
\hline & & & Treatment & 34.59 & 1,194 & $<.0001$ \\
\hline & & & Genotype $\times$ treatment & 12.46 & 1,194 & $<.0006$ \\
\hline & & \multirow[t]{3}{*}{ 5-HT } & Genotype & 19.33 & 1,230 & $<.0001$ \\
\hline & & & Treatment & 25.29 & 1,230 & $<.0001$ \\
\hline & & & Genotype $\times$ treatment & 19.19 & 1,230 & $<.0001$ \\
\hline \multirow{12}{*}{$\begin{array}{l}\text { Symptomatic } \\
\text { (SCA17: } n=5-6 / \text { group, } \\
\text { wt: } n=4-6 / \text { group) }\end{array}$} & \multirow[t]{6}{*}{ NAcc } & \multirow[t]{3}{*}{ DA } & Genotype & 2.62 & 1,185 & $>.05$ \\
\hline & & & Treatment & 17.31 & 1,185 & $<.0001$ \\
\hline & & & Genotype $\times$ treatment & 2.10 & 1,185 & $>.05$ \\
\hline & & \multirow[t]{3}{*}{$5-\mathrm{HT}$} & Genotype & 3.95 & 1,203 & .048 \\
\hline & & & Treatment & 11.73 & 1,203 & $<.0008$ \\
\hline & & & Genotype $\times$ treatment & 1.37 & 1,203 & $>.05$ \\
\hline & \multirow[t]{6}{*}{$\mathrm{CPu}$} & \multirow[t]{3}{*}{ DA } & Genotype & 3.82 & 1,185 & $>.05$ \\
\hline & & & Treatment & 22.81 & 1,185 & $<.0001$ \\
\hline & & & Genotype $\times$ treatment & 3.35 & 1,185 & $>.05$ \\
\hline & & \multirow[t]{3}{*}{$5-\mathrm{HT}$} & Genotype & 1.78 & 1,185 & $>.05$ \\
\hline & & & Treatment & 18.83 & 1,185 & $<.0001$ \\
\hline & & & Genotype $\times$ treatment & 0.39 & 1,185 & $>.05$ \\
\hline
\end{tabular}

Note: Bold value refers to statistic significance.

locomotor impairments in SCA17 animals at symptomatic age. SCA17 locomotor symptoms, however, started to emerge for pharmacologically induced locomotion.

\section{Discussion}

In this study we show that SCA17 transgenic rats display premorbid signs partially evolving into schizophrenia-like symptoms before the more typical neurological deficits are expressed. Presymptomatic SCA17 rats presented a normal sensorimotor gating and preserved AMPH-induced hyperlocomotion. Importantly, their apparent normal behaviour was complemented by significantly decreased basal extracellular monoamine levels in striatal areas and by a massively sensitized monoamine response to a single AMPH injection. At symptomatic age, SCA17 rats developed a sensorimotor gating deficit and exhibited an impaired recognition memory. Also, they showed a partially reduced locomotion after a single AMPH injection. Their basal 5-HT levels instead appeared to normalize, but DA levels in the NAcc were now elevated. The monoaminergic responses in the NAcc and DA response in the $\mathrm{CPu}$ to AMPH were still sensitized, although milder compared with the presymptomatic period. Overall, these results partially recapitulate the prodromal symptoms of schizophrenia, in which altered monoamine and particularly DA supersensitivity predates behavioural symptoms (Howes et al., 2009; Laruelle, 2000 ), and may predict the transit to psychosis in patients with schizophrenia (Fusar-Poli et al., 2012, 2016).
To our understanding, this is the first time that an animal model has borne a genetically induced neurochemical endophenotype of relevance for prodromal schizophrenia, as highlighted in the present longitudinal study. This attributes substantial face validity to our model. A gradually dysregulated DA transmission is in fact a landmark of neurodevelopmental psychosis, and the re-balance of DA neurotransmission is considered the major target for antipsychotics. A normal DA basal level plays a crucial homeostatic role in neurotransmission, in that it controls the synthesis and release of presynaptic DA (Benoit-Marand et al., 2001). Decreased DA levels can impair the DA-mediated autoinhibition and may predispose to DA supersensitivity, leading to psychosis in humans or schizophrenia-like symptoms in animals. Of note, the role of decreased monoamine levels in DA supersensitivity has already been suggested to mediate antipsychotic treatment failure in animal models (Amato, 2015; Amato et al., 2011a, 2011b, 2013, 2014) and in humans (Howes and Kapur, 2014).

Hyperdopaminergia and hyperlocomotion induced by AMPH is a simple, but widely accepted, index of psychosis in animals (Robinson and Becker, 1986). Also, 5-HT dysfunction has been associated with the expressions of psychosis (Bennett et al., 1979; Rasmussen et al., 2010), although its role is not clear (Amato, 2015). The effect of AMPH on DA release varies depending on the treatment schedule. One single injection of AMPH reportedly reverses the cytosol-to-vesicles transport by interacting with plasmalemmal and vesicular transporters (Sulzer et al., 1995). The striatal DA release upon a repeated treatment with AMPH seems, instead, to rely more on calcium conductance (Pani et al., 1990), which promotes the calcium/calmodulin-dependent kinase II 


\section{Symptomatic}

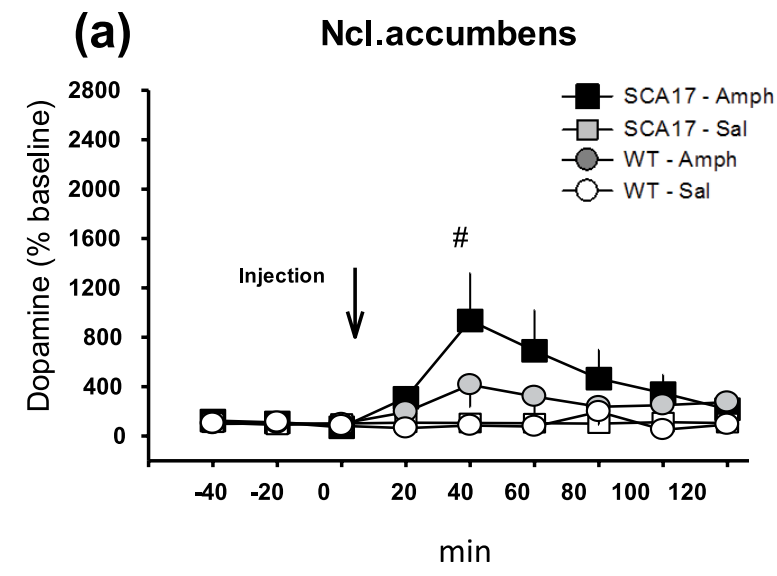

(c)

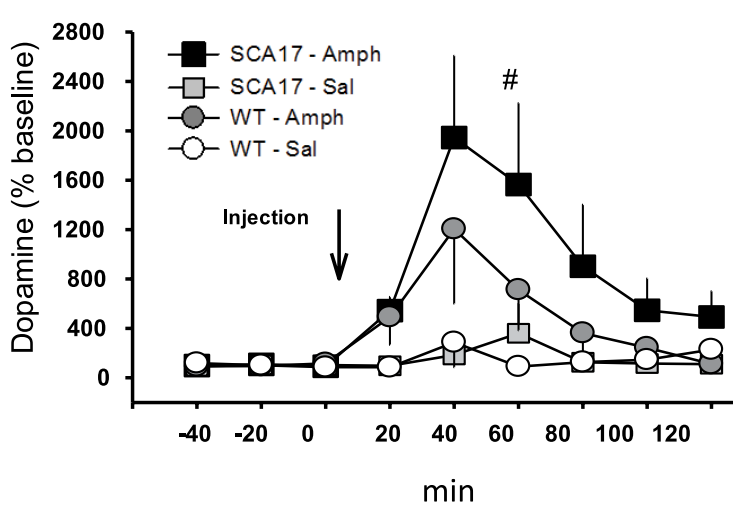

(b)

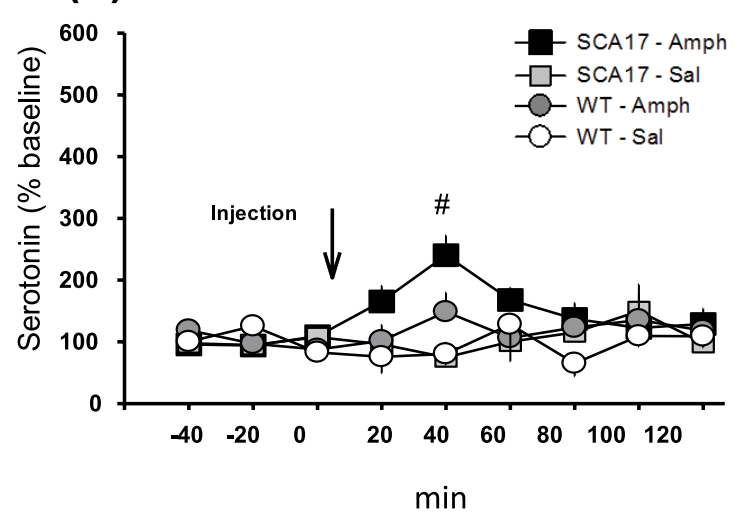

(d)

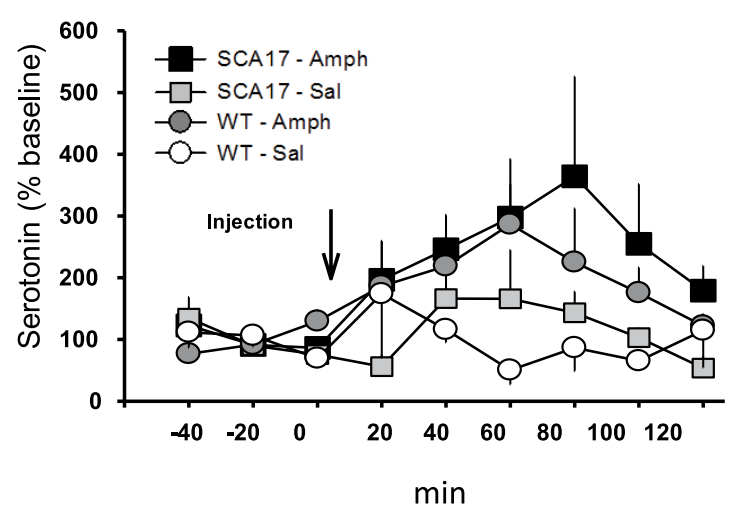

Figure 6. Amphetamine (AMPH; $1 \mathrm{mg} / \mathrm{kg}$, i.p.) or saline (Sal) effects on extracellular dopamine and serotonin levels in symptomatic SCA17 and wt rats measured by in-vivo microdialysis in freely moving animals. (a) Nucleus accumbens - dopamine. (b) Nucleus accumbens - serotonin. (c) Caudate putamen - dopamine. (d) Caudate putamen - serotonin ( ${ }^{*} p<.05 \mathrm{vs} \mathrm{wt}$ ). Please note the profound change in response magnitude compared with the presymptomatic stage.

phosphorylation of synapsin I in the striatum (Pierce and Kalivas, 1997). AMPH also interacts with the 5-HT transporters (Buchmayer et al., 2013), thus enabling the release of 5-HT in addition to DA (Pum et al. 2007). The investigation reported here was performed using a single AMPH injection. Despite this, the resulting stimulated monoamine responses to AMPH in SCA17 rats resembled the pattern of sensitization following a repeated treatment instead of merely the monoamine response to a single AMPH injection. Hence, an increased calcium conductance or a potentiated transporter-driven DA release may be responsible for the underlying sensitized monoaminergic response in SCA17 rats. Alternatively, as cortical glutamate projections into the striatum control striatal release of DA, one could also speculate that the use of ketamine as an anaesthetic could have potentiated the stimulatory AMPH effects on DA release (Moghaddam et al., 1997), thus contributing to the massive response to the latter observed in SCA17 rats. However, in the study of Moghaddam and colleagues (1997), ketamine failed to stimulate DA release in the striatum at much higher doses than the one used here. Also, our animals were anesthetized with ketamine at least 4-5 days before participating in the AMPH experiment, a time that should prevent any significant pharmacological interactions (Muller et al., 2011). Finally, it was also shown that the N-methyl-D-aspartate (NMDA) antagonist MK-801 and AMPH do not induce a cross-sensitization (Kim et al., 2011).

Our interpretation of the supersensitive DA response in SCA17 rats focuses, rather, on a decreased autoinhibition mediated by decreased basal DA activity in the striatum. Accordingly, SCA17 rats displayed low DA levels at presymptomatic age, a time when the DA response to AMPH was maximal. Symptomatic mutant rats instead showed higher DA levels at baseline, which were accompanied by a milder DA response to AMPH. Therefore, a different DA baseline in presymptomatic and symptomatic SCA17 rats may have been the underlying mechanism of the supersensitive DA response to a single injection of AMPH in SCA17 rats used in this study. Surprisingly, however, the locomotor response to AMPH of presymptomatic and symptomatic SCA17 rats did not parallel the sensitized monoamine responses, in that 


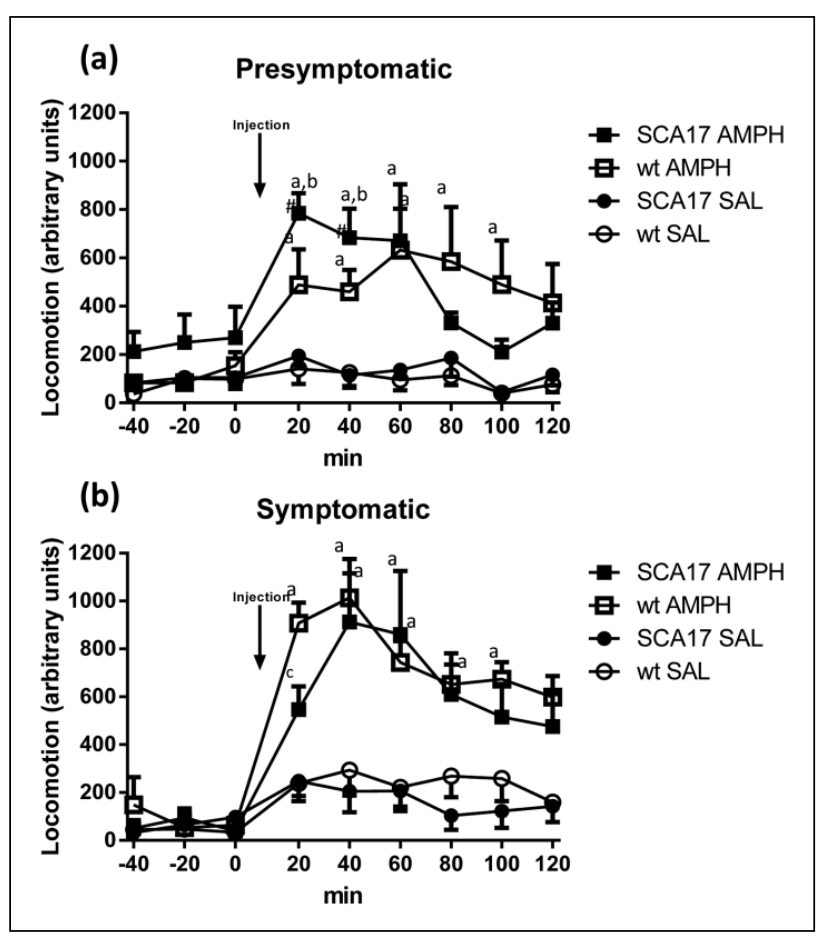

Figure 7. Amphetamine (AMPH; $1 \mathrm{mg} / \mathrm{kg}$, i.p.) or saline (Sal) effects on locomotion in presymptomatic and symptomatic SCA17 and wt rats $\left({ }^{a} p<0.05\right.$ vs. Sal; ${ }^{b} p<0.05,{ }^{c} p<0.01$ vs. wt-AMPH).

locomotor activation was not sensitized. In our view, this may be a consequence of the prominent decrease of DA in the NAcc, compared with the $\mathrm{CPu}$, in SCA17 rats (Table 2), which seems to mediate the AMPH-induced locomotion more than the dorsal striatum (Kelly et al., 1975). Alternatively, the lack of a supersensitive locomotion response to AMPH may also be interpreted as a consequence of a better locomotion control of 5-HT over the DA system. In SCA17 rats used here, the 5-HT basal level was overall higher than that of DA (Table 2). 5-HT exercises inhibition on the dopaminergic system (Amato, 2015), and lesions of the serotoninergic system enhance AMPH-induced locomotion (Green and Harvey, 1974; Lucki and Harvey, 1979; Neill et al., 1972).

PPI represents an operational measure of a sensorimotor gating and is also widely used to investigate psychotic-like symptoms in animals. It highlights a pre-attentive cognitive performance (Light et al., 2012; Nuechterlein and Dawson, 1984). Although PPI deficits are observed in several psychiatric disorders (Kohl et al., 2013), the neurobiological mechanisms of these deficits may be different in each psychiatric condition (Braff and Geyer, 1990; Swerdlow et al., 1995). Disrupted PPI in symptomatic SCA17 rats may be a consequence of a prematurely maladapted primary communication between the brainstem and the forebrain nuclei, with a particular role played by striatal DA D2 receptors. SCA17 rats with a similar mutation (Prp-TBPQ64) to the one investigated here were, in fact, found to have a lower DA D2 receptor expression in the $\mathrm{CPu}$ (Kelp et al., 2013). Furthermore, disrupted striatal signalling, mainly due to impaired striato-pallidal gamma-aminobutyric acid (GABA)ergic neurotransmission, has been suggested to underlie PPI deficits in HD (Swerdlow et al., 1990). The synergy of DA D1 and D2 receptorexpressing neurons plays an important role in mediating a normal
PPI (Ralph et al., 2001; Ralph-Williams et al., 2002). Therefore, it may be suggested that a decreased striatal DA D2 receptor expression may constitute a preliminary cause of disrupted PPI and the beginning of cognitive impairments in symptomatic SCA17 rats. An additional interpretation may be linked with the basal levels of DA discussed previously. In fact, low dopaminergic signalling at baseline in presymptomatic rats may have protected them from displaying a PPI deficit compared with symptomatic SCA17 rats with higher DA basal levels.

Cognitive deficit is a core symptom in schizophrenia, and it is predictive of long-term functional recovery. In trying to expand our investigation to this domain, we tested SCA17 rats' ability to discriminate among familiar and unfamiliar objects using the NORT, which is meant to reproduce the Measurement and Treatment Research to Improve Cognition in Schizophrenia (MATRICS) visual and learning domains (Young et al., 2009). The animal's performance on this test works as an index of object recognition memory and is commonly used to evaluate the cognitive impairments in rodent models of schizophrenia (Dere et al., 2007). We have measured SCA17 rats' performance in this test and found that their exploration of the novel object was reduced compared with that of wt rats.

The neuroanatomical substrate of the NORT performance is likely mediated by the circuit of Papez (Shah et al., 2012), which includes the cingulate cortex, the perirhinal cortex and the hippocampus. Its involvement in controlling memory functions is fundamental, and maladaptive mechanisms within this circuit underlie several neuropsychiatric diseases (Budson and Price, 2001), such as schizophrenia (Sim et al., 2006; Turetsky et al., 2003). A previous study, based on a similar transgenic rat (PrpTBPQ64), showed impaired recognition memories, possibly due to altered striatal volume (Nguyen et al., 2006). Thus, we suggest that altered striatal function may underlie the impaired performance of symptomatic SCA17 rats in the NORT. To control possible motor confounders for the observed memory deficit in SCA17 rats, as revealed by NORT, we also screened horizontal exploratory behaviour during the test (Figure 3, no differences) and basic locomotor coordination using the accelerod test and found that SCA17 and wt rats performed equally at both presymptomatic and symptomatic ages (data not shown). Thus, the differences in exploration time between the two groups could not be attributed to potential motor deficits. Of note, the performance of all animals in the accelerod test was decreased at symptomatic age, probably as a consequence of older age and increased body weight (data not shown).

\section{Advantages and limitations of the study}

The dysregulation of monoamine levels at baseline and in response to a single injection of AMPH before behavioural deficits with psychological relevance are expressed over a longitudinal period is the core translational result of the present study. In our view, this outcome contributes significantly to the face validity of the SCA17 mutation as a model of prodromal symptoms of schizophrenia.

However, the present study also displays a number of issues that will need to be addressed in future studies. For example, the DA basal levels in wt control rats decreased as consequence of their age, probably due to a natural age-related loss of 
dopaminergic neurons (Mortera and Herculano-Houzel, 2012). The opposite pattern was instead observed in mutant rats. This apparent functional re-balance of DA in SCA17 rats is currently not understood. In addition to the DA-5-HT interaction discussed above, one may also argue that combinatory adaptations, different from those occurring in wt, underlie the neuroplasticity associated with the release and re-uptake machinery of DA. Thus, when the neurodegeneration is at an advanced stage, compensative adaptation processes come into play to maintain extracellular DA levels around normal (Sarre et al., 2004; Snyder et al., 1990). Conversely, when the DA neurodegeneration is at the initial stage, DA levels decrease because compensatory adaptations have yet to take place. In the specific case here, the lack of neurochemical stability in control rats over the longitudinal investigation weakens our interpretations of mutant rats' symptomatology. Furthermore, compared with human conditions affected by either schizophrenia or SCA17, the psychosis-like symptoms developed by SCA17 rats were not as strong as we expected. While the PPI was clearly impaired at symptomatic age compared with the presymptomatic age of SCA17 rats and compared with wt controls, their AMPH-induced hyperlocomotion was not different between the two ages as compared with wt. This outcome may be a consequence of three different factors. First, presymptomatic and symptomatic SCA17 rats may already carry a subtle neurological disorder, linked to the type of genetic mutation used here, which did not allow the proper expression of locomotion. Second, it may also be that only a proportion of SCA17 rats developed a schizophrenia-like phenotype. In fact, we have evaluated our SCA17 rats as a homogeneous group. But probably, we would have had more chance of highlighting a stronger phenotype if we had generated a subgroup of rats depending on their locomotion response to AMPH. For this purpose, we should have used a larger number of rats. Third, although genetic heredity is a key factor leading to schizophrenia, the environment interacting with genes is suggested to trigger the expression of a more severe phenotype (van Os et al., 2010). Our SCA17 rats developed a schizophrenia-like phenotype in the absence of environmental factors, which, if put into play, could have accelerated or given rise to a more severe phenotype.

The evaluation of the memory performance confined to the symptomatic period of SCA17 rats is a potential limitation of the present study. However, given the limited extent of the cognitive impairment measured in symptomatic SCA17 rats, there is unlikely to have been a significant deficit during the presymptomatic period.

\section{Conclusion}

Although it is still difficult to recapitulate the number and the quality of schizophrenia symptoms in an animal, the SCA17 rat model herein investigated bears the neurochemical phenotype of prodromal schizophrenia. Although we acknowledge that the SCA17 mutation may not directly cause the symptoms of schizophrenia, it may have led to a disruption of monoamine signalling early in adulthood, which may initially be compensated for at the physiological level and, thus, not directly result in behavioural impairments. Of note, the schizophrenia-like symptoms in SCA17 rats occurred in response to the genetic manipulation alone, in the absence of a stressful environment that probably would have accelerated the expression of the symptomatology.

\section{Acknowledgements}

We thank Dr Katharina Schieber, Dr Nurul Hasnida Binti Mohammad Yusoff, Dr Farah Wahida Binti Suhaimi and Ms Sally Makady for their assistance during the experiments.

\section{Declaration of Conflicting Interests}

The authors declared no potential conflicts of interest with respect to the research, authorship, and/or publication of this article.

\section{Funding}

The authors disclosed receipt of the following financial support for the research, authorship, and/or publication of this article: This work was supported by German ELAN and DFG MU2789/7-1 grants. O.R. and S.v.H. were supported by the European Community 'RATstream STREP project' (grant \#037846).

\section{References}

Amato D (2015) Serotonin in antipsychotic drugs action. Behavioural Brain Research 277: 125-135.

Amato D, Canneva F, Maschauer S, et al. (2013) A mechanism of antipsychotic treatment failure and its reversal. European Neuropsychopharmacology 23 (Suppl. 2): S455.

Amato D, Müller CP, Canneva F, et al. (2014) Mechanisms of antipsychotic treatment failure. Abstract of the 4th Biennal Schizophrenia International Research Conference. Schizophrenia Research 153(Suppl 69): S1-S384.

Amato D, Natesan S, Kapur S, et al. (2011a) Haloperidol modulates noradrenergic responses to aversive stimulation depending on treatment duration. Behavioural Brain Research 221: 311-313.

Amato D, Natesan S, Yavich L, et al. (2011b) Dynamic regulation of dopamine and serotonin responses to salient stimuli during chronic haloperidol treatment. International Journal of Neuropsychopharmacoly 14: 1327-1339.

Amato D, Pum ME, Groos D, et al. (2015) Neuropharmacology of lightinduced locomotor activation. Neuropharmacology 95: 243-251.

Bauer PO and Nukina N (2009) The pathogenic mechanisms of polyglutamine diseases and current therapeutic strategies. Journal of Neurochemistry 110: 1737-1765.

Bennett JP, Jr, Enna SJ, Bylund DB, et al. (1979) Neurotransmitter receptors in frontal cortex of schizophrenics. Archives of General Psychiatry 36: 927-934.

Benoit-Marand M, Borrelli E and Gonon F (2001) Inhibition of dopamine release via presynaptic D2 receptors: Time course and functional characteristics in vivo. Journal of Neuroscience 21: 9134-9141.

Bevins RA and Besheer J (2006) Object recognition in rats and mice: A one-trial non-matching-to-sample learning task to study 'recognition memory'. Nature Protocols 1: 1306-1311.

Braff DL and Geyer MA (1990) Sensorimotor gating and schizophrenia. Human and animal model studies. Archives of General Psychiatry 47: 181-188.

Buchmayer F, Schicker K, Steinkellner T, et al. (2013) Amphetamine actions at the serotonin transporter rely on the availability of phosphatidylinositol-4,5-bisphosphate. Proceedings of the National Academy of Sciences of the United States of America 110: 11642-11647.

Budson AE and Price BH (2001) Memory: Clinical disorders. In Encyclopedia of Life Sciences. London: Macmillan Publishers Ltd, Nature Publishing Group.

Chen CM, Lane HY, Wu YR, et al. (2005) Expanded trinucleotide repeats in the TBP/SCA17 gene mapped to chromosome 6q27 are associated with schizophrenia. Schizophrenia Research 78: 131-136.

Claes S, Van Zand K, Legius E, et al. (1995) Correlations between triplet repeat expansion and clinical features in Huntington's disease. Archives of Neurology 52: 749-753. 
Dere E, Huston JP and De Souza Silva MA (2007) The pharmacology, neuroanatomy and neurogenetics of one-trial object recognition in rodents. Neuroscience Biobehavioral Reviews 31: 673-704.

Fusar-Poli P, Bonoldi I, Yung AR, et al. (2012) Predicting psychosis: Meta-analysis of transition outcomes in individuals at high clinical risk. Archives of General Psychiatry 69: 220-229.

Fusar-Poli P, Cappucciati M, Borgwardt S, et al. (2016) Heterogeneity of psychosis risk within individuals at clinical high risk: A metaanalytical stratification. JAMA Psychiatry 73: 113-120.

Gaitonde EJ, Sivagnanasundaram S, Morris AG, et al. (1997) The number of triplet repeats in five brain-expressed loci with CAG repeats is not associated with schizophrenia. Schizophrenia Research 25: $111-116$.

Green TK and Harvey JA (1974) Enhancement of amphetamine action after interruption of ascending serotonergic pathways. Journal of Pharmacology and Experimental Therapeutics 190: 109-117.

Holzmann C, Maueler W, Petersohn D, et al. (1998) Isolation and characterization of the rat huntingtin promoter. Biochemical Journal 336 (Pt 1): 227-234.

Hong KS, Won HH, Cho EY, et al. (2009) Genome-widely significant evidence of linkage of schizophrenia to chromosomes 2p24.3 and 6q27 in an SNP-based analysis of Korean families. American Journal of Medical Genetics. Part B, Neuropsychiatric Genetics 150B: 647-652.

Howes OD, Kambeitz J, Kim E, et al. (2012) The nature of dopamine dysfunction in schizophrenia and what this means for treatment. Archives of General Psychiatry 69: 776-786.

Howes OD and Kapur S (2014) A neurobiological hypothesis for the classification of schizophrenia: Type A (hyperdopaminergic) and type B (normodopaminergic). British Journal of Psychiatry 205: 1-3.

Howes OD, Montgomery AJ, Asselin MC, et al. (2009) Elevated striatal dopamine function linked to prodromal signs of schizophrenia. Archives of General Psychiatry 66: 13-20.

Jones AL, Middle F, Guy C, et al. (1997) No evidence for expanded polyglutamine sequences in bipolar disorder and schizophrenia. Molecular Psychiatry 2: 478-482.

Kelly PH, Seviour PW and Iversen SD (1975) Amphetamine and apomorphine responses in the rat following 6-OHDA lesions of the nucleus accumbens septi and corpus striatum. Brain Research 94: 507-522.

Kelp A, Koeppen AH, Petrasch-Parwez E, et al. (2013) A novel transgenic rat model for spinocerebellar ataxia type 17 recapitulates neuropathological changes and supplies in vivo imaging biomarkers. Journal of Neuroscience 33: 9068-9081.

Kim MN, Jutkiewicz EM, Zhang M, et al. (2011) The sensitizing effect of acute nicotine on amphetamine-stimulated behavior and dopamine efflux requires activation of beta2 subunit-containing nicotinic acetylcholine receptors and glutamate $\mathrm{N}$-methyl-D-aspartate receptors. Neuropharmacology 60: 1126-1134.

Kohl S, Heekeren K, Klosterkotter J, et al. (2013) Prepulse inhibition in psychiatric disorders - apart from schizophrenia. Journal of Psychiatric Research 47: 445-452.

Koide R, Kobayashi S, Shimohata T, et al. (1999) A neurological disease caused by an expanded CAG trinucleotide repeat in the TATA-binding protein gene: A new polyglutamine disease? Human Molecular Genetics 8: 2047-2053.

Laruelle M (2000) The role of endogenous sensitization in the pathophysiology of schizophrenia: Implications from recent brain imaging studies. Brain Research. Brain Research Reviews 31: 371-384.

Light GA, Swerdlow NR, Rissling AJ, et al. (2012) Characterization of neurophysiologic and neurocognitive biomarkers for use in genomic and clinical outcome studies of schizophrenia. PLoS One 7: e39434.

Lucki I and Harvey JA (1979) Increased sensitivity to d- and 1-amphetamine action after midbrain raphe lesions as measured by locomotor activity. Neuropharmacology 18: 243-249.

Moghaddam B, Adams B, Verma A, et al. (1997) Activation of glutamatergic neurotransmission by ketamine: A novel step in the pathway from NMDA receptor blockade to dopaminergic and cognitive disruptions associated with the prefrontal cortex. Journal of Neuroscience 17: 2921-2927.

Morris AG, Gaitonde E, McKenna PJ, et al. (1995) CAG repeat expansions and schizophrenia: Association with disease in females and with early age-at-onset. Human Molecular Genetics 4: 1957-1961.

Mortera P and Herculano-Houzel S (2012) Age-related neuronal loss in the rat brain starts at the end of adolescence. Frontiers in Neuroanatomy 6: 45

Muller CP, Pum ME, Amato D, et al. (2011) The in vivo neurochemistry of the brain during general anesthesia. Journal of Neurochemistry 119: 419-446.

Neill DB, Grant LD and Grossman SP (1972) Selective potentiation of locomotor effects of amphetamine by midbrain raphe lesions. Physiology \& Behavior 9: 655-657.

Nguyen HP, Kobbe P, Rahne H, et al. (2006) Behavioral abnormalities precede neuropathological markers in rats transgenic for Huntington's disease. Human Molecular Genetics 15: 3177-3194.

Nuechterlein KH and Dawson ME (1984) Information processing and attentional functioning in the developmental course of schizophrenic disorders. Schizophrenia Bulletin 10: 160-203.

O'Donovan MC, Guy C, Craddock N, et al. (1996) Confirmation of association between expanded CAG/CTG repeats and both schizophrenia and bipolar disorder. Psychological Medicine 26: $1145-1153$.

Ohi K, Hashimoto R, Yasuda Y, et al. (2009) TATA box-binding protein gene is associated with risk for schizophrenia, age at onset and prefrontal function. Genes, Brain, and Behavior 8: 473-480.

Pani L, Carboni S, Kusmin A, et al. (1990) Nimodipine inhibits cocaineinduced dopamine release and motor stimulation. European Journal of Pharmacology 176: 245-246.

Paxinos G and Watson C (1986) The Rat Brain in Stereotactic Coordinates. New York: Academic.

Pierce RC and Kalivas PW (1997) Repeated cocaine modifies the mechanism by which amphetamine releases dopamine. Journal of Neuroscience 17: 3254-3261.

Pum M, Carey RJ, Huston JP, et al. (2007) Dissociating effects of cocaine and d-amphetamine on dopamine and serotonin in the perirhinal, entorhinal, and prefrontal cortex of freely moving rats. Psychopharmacology (Berl) 193: 375-390.

Quednow BB, Geyer MA and Halberstadt AL (2010) Serotonin and Schizophrenia. In: Müller CP and Jacobs BL (eds) Handbook of the Behavioral Neurobiology of Serotonin. London: Academic Press, pp. 585-620.

Ralph RJ, Paulus MP, Fumagalli F, et al. (2001) Prepulse inhibition deficits and perseverative motor patterns in dopamine transporter knockout mice: Differential effects of D1 and D2 receptor antagonists. Journal of Neuroscience 21: 305-313.

Ralph-Williams RJ, Lehmann-Masten V, Otero-Corchon V, et al. (2002) Differential effects of direct and indirect dopamine agonists on prepulse inhibition: A study in D1 and D2 receptor knock-out mice. Journal of Neuroscience 22: 9604-9611.

Rasmussen H, Erritzoe D, Andersen R, et al. (2010) Decreased frontal serotonin $2 \mathrm{~A}$ receptor binding in antipsychotic-naive patients with first-episode schizophrenia. Archives of General Psychiatry 67: 9-16.

Riley BE and Orr HT (2006) Polyglutamine neurodegenerative diseases and regulation of transcription: Assembling the puzzle. Genes \& Development 20: 2183-2192.

Robinson TE and Becker JB (1986) Enduring changes in brain and behavior produced by chronic amphetamine administration: A review and evaluation of animal models of amphetamine psychosis. Brain Research 396: 157-198.

Rolfs A, Koeppen AH, Bauer I, et al. (2003) Clinical features and neuropathology of autosomal dominant spinocerebellar ataxia (SCA17). Annals of Neurology 54: 367-375.

Rubinsztein DC, Leggo J, Crow TJ, et al. (1996) Analysis of polyglutamine-coding repeats in the TATA-binding protein in different 
human populations and in patients with schizophrenia and bipolar affective disorder. American Journal of Medical Genetics 67: 495-498.

Sarre S, Yuan H, Jonkers N, et al. (2004) In vivo characterization of somatodendritic dopamine release in the substantia nigra of 6-hydroxydopamine-lesioned rats. Journal of Neurochemistry 90: 29-39.

Shah A, Jhawar SS and Goel A (2012) Analysis of the anatomy of the Papez circuit and adjoining limbic system by fiber dissection techniques. Journal of Clinical Neuroscience 19: 289-298.

Sim K, DeWitt I, Ditman T, et al. (2006) Hippocampal and parahippocampal volumes in schizophrenia: A structural MRI study. Schizophrenia Bulletin 32: 332-340.

Sirugo G, Deinard AS, Kidd JR, et al. (1997) Survey of maximum CTG/ CAG repeat lengths in humans and non-human primates: Total genome scan in populations using the Repeat Expansion Detection method. Human Molecular Genetics 6: 403-408.

Snyder GL, Keller RW, Jr and Zigmond MJ (1990) Dopamine efflux from striatal slices after intracerebral 6-hydroxydopamine: Evidence for compensatory hyperactivity of residual terminals. Journal of Pharmacology and Experimental Therapeutics 253: 867-876.

Sulzer D, Chen TK, Lau YY, et al. (1995) Amphetamine redistributes dopamine from synaptic vesicles to the cytosol and promotes reverse transport. Journal of Neuroscience 15: 4102-4108.

Swerdlow NR, Braff DL and Geyer MA (1990) GABAergic projection from nucleus accumbens to ventral pallidum mediates dopamineinduced sensorimotor gating deficits of acoustic startle in rats. Brain Research 532: 146-150.

Swerdlow NR, Paulsen J, Braff DL, et al. (1995) Impaired prepulse inhibition of acoustic and tactile startle response in patients with Huntington's disease. Journal of Neurology, Neurosurgery, and Psychiatry 58: 192-200.
Tsuang D, Almqvist EW, Lipe H, et al. (2000) Familial aggregation of psychotic symptoms in Huntington's disease. American Journal of Psychiatry 157: 1955-1959.

Tsuang D, DiGiacomo L, Lipe H, et al. (1998) Familial aggregation of schizophrenia-like symptoms in Huntington's disease. American Journal of Medical Genetics 81: 323-327.

Turetsky BI, Moberg PJ, Roalf DR, et al. (2003) Decrements in volume of anterior ventromedial temporal lobe and olfactory dysfunction in schizophrenia. Archives of General Psychiatry 60: 1193-1200.

Urbach YK, Raber KA, Canneva F, et al. (2014) Automated phenotyping and advanced data mining exemplified in rats transgenic for Huntington's disease. Journal of Neuroscience Methods 234: 38-53.

Urbach YK, Raber KA, Nguyen HP, et al. (2009) Comprehensive classical and automated phenotyping reveals a schizophrenic-like, clozapine-responsive phenotype in a transgenic rat model for spinocerebellar ataxia (SCA17). EMBL Workshop on Translating Behaviour: Bridging Clinical and Animal Model Research, Heidelberg, Germany, 14-16 November 2009.

van Os J, Kenis G and Rutten BP (2010) The environment and schizophrenia. Nature 468: 203-212.

van Roon-Mom WM, Reid SJ, Faull RL, et al. (2005) TATA-binding protein in neurodegenerative disease. Neuroscience 133: 863-872.

von Horsten S, Schmitt I, Nguyen HP, et al. (2003) Transgenic rat model of Huntington's disease. Human Molecular Genetics 12: 617-624.

Young JW, Powell SB, Risbrough V, et al. (2009) Using the MATRICS to guide development of a preclinical cognitive test battery for research in schizophrenia. Pharmacology \& Therapeutics 122: 150-202.

Zappacosta B, Monza D, Meoni C, et al. (1996) Psychiatric symptoms do not correlate with cognitive decline, motor symptoms, or CAG repeat length in Huntington's disease. Archives of Neurology 53: 493-497.

Zoghbi HY and Orr HT (2000) Glutamine repeats and neurodegeneration. Annual Review of Neuroscience 23: 217-247. 